\title{
A Kinetic Study on the Oxidation of Indole by Peroxomonosulphate in Acetonitrile Solvent
}

\author{
Muniyappan Kavery*, Chandramohan Govindasamy ${ }^{\dagger}$, and Stephen Johnson* \\ Bharathiar University, Coimbatore - 641046, Tamil Nadu, India. *E-mail: muni.kavery@gmail.com \\ 'Dept of Chemistry, A.V.V.M.S.P College, Poondi, 613503, Tamil Nadu, India \\ \$harathiar University, Coimbatore - 641046, Tamil Nadu, India
}

(Received September 5, 2012; Accepted February 19, 2013)

\begin{abstract}
Kinetics of oxidation of indole by peroxomonosulphate (PMS) in aqueous acetonitrile medium has been investigated. The reaction follows a total second order, first order each with respect to [Indole] and [PMS]. The rate of the reaction was not affected by added $\left[\mathrm{H}^{+}\right]$. Variation of ionic strength $(\mu)$ had no influence on the rate. Increase of percentage of acetonitrile decreased the rate. Absen ce of any polymerization indicated a nonradical pathway. Activation and thermodynamic parameters have bee $\mathrm{n}$ computed. A suitable kinetic scheme based on these observations is proposed. The reactivity of PMS towards Indole was found to be higher than that with peroxodisulphate.
\end{abstract}

Key words: Kinetics, Mechanism, Oxidation, Indole, Peroxomonosulphate (PMS)

\section{INTRODUCTION}

Indole is an electron rich hetero-atomic, nitrogen containing compound which appears in various naturally occurring compounds such as alkaloids and tryptophan metabolities. ${ }^{1}$ Metabolites of Indole can be produced by bacteria, by the degradation of the amino acid tryptophan. At very low concentrations, it has a flowery smell and is a constituent of many flowerscents (such as orange blossoms) and perfumes. It also occurs in coal-tar. The name indole arises from the words indigo and oleum, since indole was first isolated by treatment of the indigo dye with oleum. Indoles and bromoindoles are compounds with high potential for applications in various domains, especially in the electrochemical industry as electro catalysts, anode Materials in batteries, anticorrosion coating, and fast response potentiometric sensors. ${ }^{2,3}$ These compounds have also attracted considerable attention in pharmacology, mainly because of their ability to develop antifungal and antibacterial agents. They also act as candidates for direct oxidation/reductionof biomolecules, and other biological activities. ${ }^{4}$

The oxidation of indole into oxindole was carried out by using various oxidants such as $\mathrm{N}$-chloro- $\mathrm{N}$-sodio-p-toluenesulphonamide in alkaline medium catalysed by osmium (VIII), ${ }^{5}$ chromium(VI) ${ }^{6}$ oxidation catalysed by ethylene diamine tetraacetic acid, oxalic acid, picolinic acid, peroxide oxidation of indole catalysed by chloroperoxidases, ${ }^{7}$ oxidation of indole and indolederivatives catalysed by non- heme chloroperoxidases ${ }^{8}$ and oxidation of indole by cytochrome P450 enzymes. ${ }^{9}$ The hazardous nature of elemental bromineand difficulties encountered in its handling have led to preparation ${ }^{10}$ of new active bromine reagents like tetra alkyl ammonium tribromides. These reagents can be synthesized ${ }^{11}$ very easily by oxidizing bromide to tribromide and then precipitating with quaternary ammonium cation.

Oxidation of indole-3-acetic acid by dioxygen, ${ }^{12} \mathrm{Ce}(\mathrm{IV}),{ }^{12}$ 1,10-phenanthroline-manganese (II) complexes, ${ }^{13}$ hydrogen peroxide, ${ }^{14}$ ferric salts, ${ }^{14}$ nitrite ion, ${ }^{14}$ potassium persulphate, ${ }^{14} \mathrm{~N}$-chlorosuccinimide, ${ }^{14} \mathrm{~N}$-bromosuccinimide and sodium hypochlorite ${ }^{14}$ has been reported. Chlorophyll sensitized photo-oxidation, ${ }^{15}$ peanut peroxidase, ${ }^{16}$ horseradish, and tobacco peroxidases ${ }^{17}$ catalysed oxidation of indole-3-acetic acid have been studied. Electrochemical and peroxidase oxygen-mediated oxidation of indole-3acetic acid at physiological $\mathrm{pH}$ has been reported. ${ }^{18}$ In view of this, the present work is significant as it involves the reaction of a peroxo linkage containing oxidant namely PMS with indole. Although the oxidation of certain substituted indoles such as 2,3-dialkyl indoles by peroxodisulphate, ${ }^{19} \mathrm{PMS},{ }^{19}$ peroxomonophosphoric, ${ }^{19}$ peroxodiphosphoric ${ }^{19}$ acids has been already reported in the literature, Although the oxidation of indoles by tetrabutylammoniumtribromide (TBATB) has been already reported in the literature, the lack of kinetic and mechanistic investigation on the oxidation of Indole by PMS investigated us to carry out this work and is presented as a first report in this study. 


\section{EXPERIMENTAL}

\section{Materials}

Indole (Qualigens, India) of highest purity grade available was used as such. PMS was obtained from E.I. Du Pont de Nemours Company, U.S.A. under the other name 2,3-Benzopyrrole, ketole, 1-benzazole. Solutions of this salt were assayed iodometrically and by cerimetry. ${ }^{20}$ Other chemicals and reagents such as sulphuric acid, acetonitrile, sodium bisulphate, and acrylonitrile used were of analytical grade with $99.9 \%$ purity. Water distilled from Kilburn Manesty still was again distilled over alkaline permanganate in an all-glass pyrex vessel. All reagents and solutions were prepared using this doubly distilled water.

\section{Kinetic Measurements}

Kinetic studies were carried out in 50\% (v/v) aqueous acetonitrile medium under pseudo first-order conditions with a large excess of indole over PMS in the temperature range of 283-293 K. The reaction was followed by estimating the unreacted PMS as a function of time by using the iodometric method. The liberated iodine was titrated against standard sodium thiosulphate solution by using starch as indicator. From the titre values, plots of $\log$ [PMS] vs time were made and from the slope of such plots, the pseudofirst order rate constants, $k\left(\mathrm{~s}^{-1}\right)$ were obtained. It was checked that the results were reproducible within $\pm 5 \%$ error.

\section{Product Analysis}

A reaction mixture containing slight excess of PMS $(0.125 \mathrm{M})$, Indole $(0.05 \mathrm{M})$, and acetonitrile-water mixture was kept aside at room temperature for a day, so that the substrate was completely converted into product. The mixture was extracted with ether. A resinuous mass was obtained in the ether layer and it could not be identified. The aqueous layer was treated with acetone and filtered. No compound was detected from the filtrate. Now the solid mass was treated with methanol and filtered. The final product was obtained from the alcoholic solution and identified by IR (Fig. 1) and NMR spectra. The above product was identified as Isatin.

The proton NMR spectrum of the product obtained in our experiment showed distinctly different features from that of the starting material, Indole. That is the product spectrum exhibited signals at $\delta=8.1$ corresponding to $>\mathrm{NH}$, another at $\delta=7.1-7.8$ corresponding to benzene aromatic ring.

\section{RESULTS AND DISCUSSION}

Factors influencing the rate of oxidation of [Indole] by PMS such as effects of (i) [Indole $]_{0}$, (ii) $[\mathrm{PMS}]_{0}$, (iii) ionic strength $(\mu)$, (iv) $\left[\mathrm{H}^{+}\right]_{0}$, and $(\mathrm{v})$ dielectric constant have been studied. Rate and activation parameters were evaluated.

(i) Effect of [Indole $]_{0}$ : At a constant $[\mathrm{PMS}],\left[\mathrm{H}^{+}\right], \mu$, and fixed percentage of acetonitrile, kinetic runs were carried out with various initial concentrations of Indole, which yielded [Indole] dependent rate constants. The values of pseudofirst-order rate constants $k\left(\mathrm{~s}^{-1}\right)$ thus obtained were found to increase with [Indole] (Table $1 \&$ Fig. 2) over a range of [Indole] used $\left(2.0 \times 10^{-2}-4.0 \times 10^{-2} \mathrm{~mol}\right.$ $\mathrm{dm}^{-3}$ ). This shows that the reaction obeys first order with respect to [Indole]. This was confirmed by the linear plots of $k^{\prime}\left(\mathrm{s}^{-1}\right)$ vs [Indole] passing through origin $(r=0.999)$ (Fig. 3). Such a kinetic behaviour indicates the absence of any self-decomposition of PMS. ${ }^{21}$ In the oxidations of
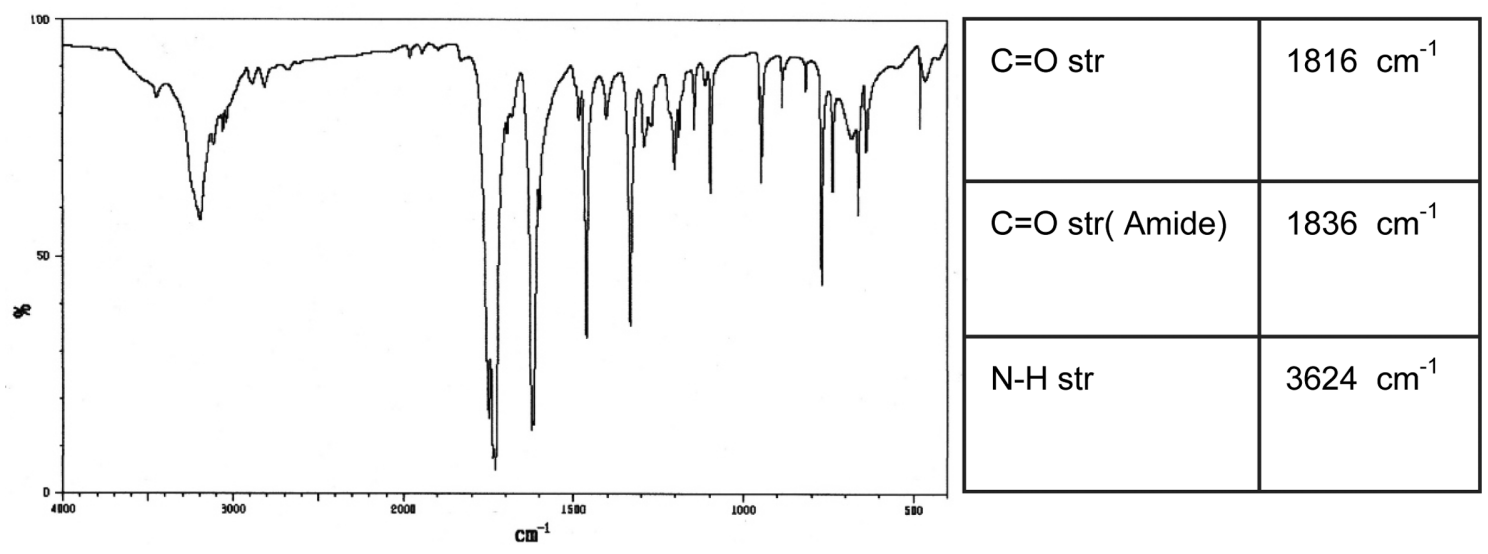

Fig. 1. FT-IR spectrum of product. 
Table 1. Effect of [Indole]

\begin{tabular}{cccc}
\hline [Indole $^{a}$ & \multicolumn{3}{c}{$k^{\prime}\left(10^{4} \mathrm{~s}^{-1}\right)$} \\
\cline { 2 - 4 }$\left(10^{2} \mathrm{~mol} \mathrm{dm}\right.$ \\
\cline { 2 - 4 } & $283 \mathrm{~K}$ & $288 \mathrm{~K}$ & $293 \mathrm{~K}$ \\
\hline 2.0 & 2.0381 & 2.6254 & 3.1167 \\
2.5 & 2.5179 & 3.1896 & 3.8306 \\
3.0 & 3.0092 & 3.8383 & 4.5349 \\
3.5 & 3.6310 & 4.4870 & 5.1280 \\
4.5 & 4.0878 & 5.0358 & 6.0914 \\
\hline
\end{tabular}

$\bar{a}[\mathrm{PMS}]: 2.0 \times 10^{-3} \mathrm{~mol} \mathrm{dm}^{-3},\left[\mathrm{H}^{+}\right]: 0.02 \mathrm{~mol} \mathrm{dm}^{-3}, \mu: 0.3 \mathrm{~mol} \mathrm{dm}^{-3}$, $\mathrm{CH}_{3} \mathrm{CN}: 50 \%$.

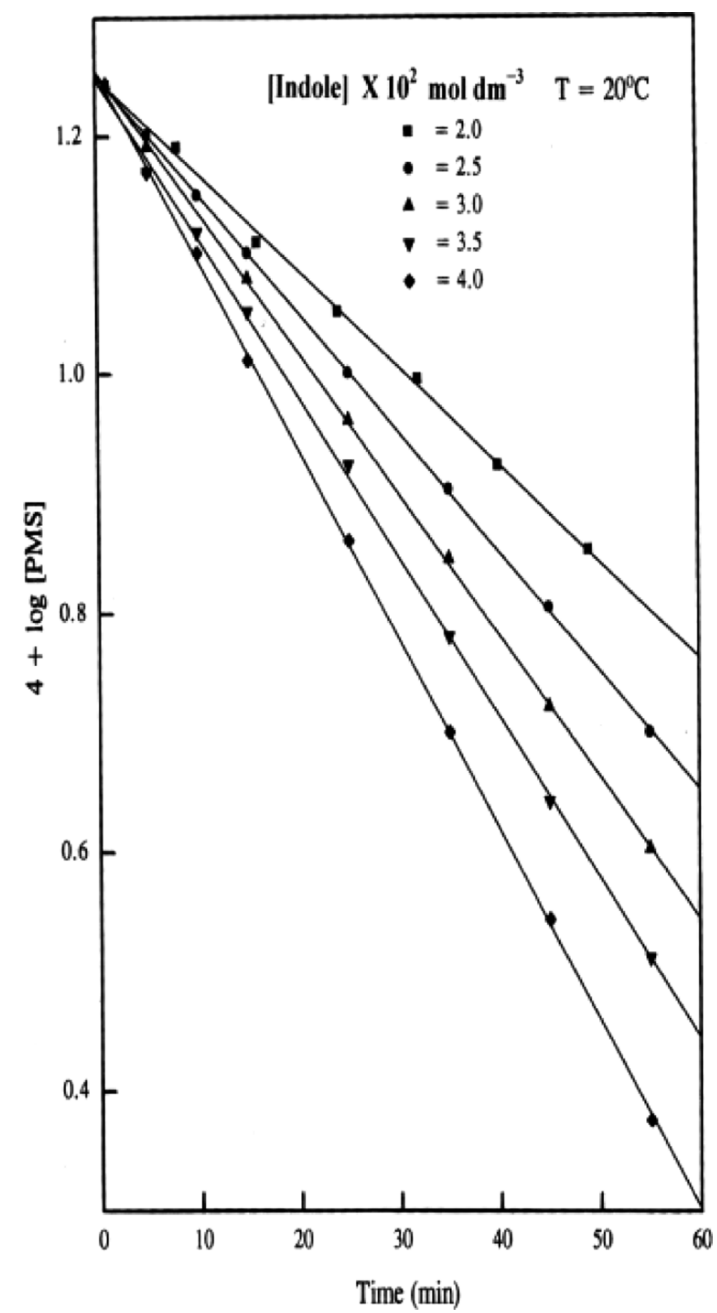

Fig. 2. Variation of [Indole].

variety of organic compounds by PMS, such observations have been made. The value of $k_{2}\left(\mathrm{~mol}^{-1} \mathrm{dm}^{3} \mathrm{~s}^{-1}\right)$ was evaluated from the slope of $k^{\prime}\left(\mathrm{s}^{-1}\right)$ vs [Indole] plots. The $k_{2}\left(\mathrm{~mol}^{-1} \mathrm{dm}^{3} \mathrm{~s}^{-1}\right)$ values thus obtained $(r=0.999)$ from such plots were in agreement with the corresponding values calculated from the factor $k^{\prime}\left(\mathrm{s}^{-1}\right) /[$ Indole].

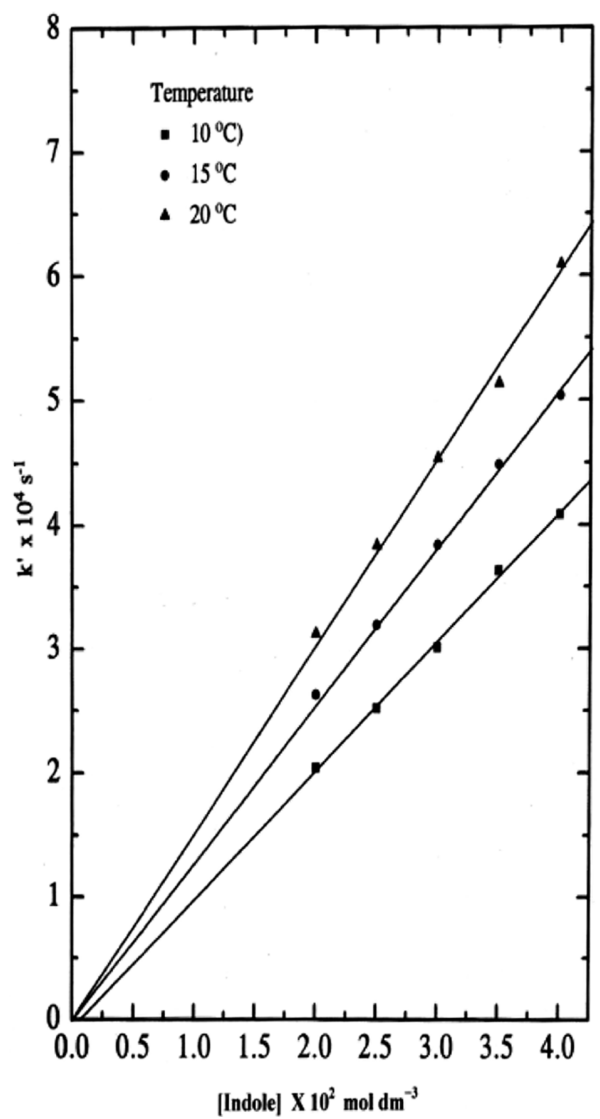

Fig. 3. Evaluation of $k_{2}$.

Table 2. (A) Effect of [PMS] at $293 \mathrm{~K}$

\begin{tabular}{cc}
\hline$[\mathrm{PMS}]^{a}\left(10^{-3} \mathrm{~mol} \mathrm{dm}^{-3}\right)$ & $k^{\prime}\left(10^{4} \mathrm{~s}^{-1}\right)$ \\
\hline 1.0 & 4.5637 \\
2.0 & 4.5369 \\
3.0 & 4.5177 \\
4.0 & 4.5253 \\
\hline${ }^{a}\left[\right.$ [ndole]: $3.0 \times 10^{-3} \mathrm{~mol} \mathrm{dm}^{-3},\left[\mathrm{H}^{+}\right]: 0.02 \mathrm{~mol} \mathrm{dm}^{-3}, \mu: 0.3 \mathrm{~mol} \mathrm{dm}^{-3}$
\end{tabular}

[Indole]: $3.0 \times 10^{-3} \mathrm{~mol} \mathrm{dm}^{-3},\left[\mathrm{H}^{+}\right]: 0.02 \mathrm{~mol} \mathrm{dm}^{-3}, \mu: 0.3 \mathrm{~mol} \mathrm{dm}^{-3}$, $\mathrm{CH}_{3} \mathrm{CN}: 50 \%$.

(B) Effect of $\mu$ at $293 \mathrm{~K}$

\begin{tabular}{cc}
\hline$\mu^{b}\left(\mathrm{~mol} \mathrm{dm}^{-3}\right)$ & $k^{\prime}\left(10^{4} \mathrm{~s}^{-1}\right)$ \\
\hline 0.1 & 4.5560 \\
0.2 & 4.5599 \\
0.3 & 4.5369 \\
0.4 & 4.5597 \\
\hline
\end{tabular}

${ }^{b}\left[\right.$ Indole]: $3.0 \times 10^{-2} \mathrm{~mol} \mathrm{dm}^{-3}$, [PMS]: $2.0 \times 10^{-3} \mathrm{~mol} \mathrm{dm}^{-3},\left[\mathrm{H}^{+}\right]$: $0.02 \mathrm{~mol} \mathrm{dm}^{-3}, \mathrm{CH}_{3} \mathrm{CN}: 50 \%$.

(C) Effect of $\left[\mathrm{H}^{+}\right]$at $293 \mathrm{~K}$

\begin{tabular}{cc}
\hline$\left[\mathrm{H}^{+}\right]^{c}\left(\mathrm{~mol} \mathrm{dm}^{-3}\right)$ & $k^{\prime}\left(10^{4} \mathrm{~s}^{-1}\right)$ \\
\hline 0.005 & 4.5023 \\
0.020 & 4.5369 \\
0.050 & 4.6021 \\
0.090 & 4.5906 \\
\hline${ }^{c}$ Indole]: $3.0 \times 10^{-2} \mathrm{~mol} \mathrm{dm}{ }^{-3},[\mathrm{PMS}]:$ & $2.0 \times 10^{-3} \mathrm{~mol} \mathrm{dm}^{-3},\left[\mathrm{H}^{+}\right]:$ \\
$0.02 \mathrm{~mol} \mathrm{dm}$
\end{tabular}




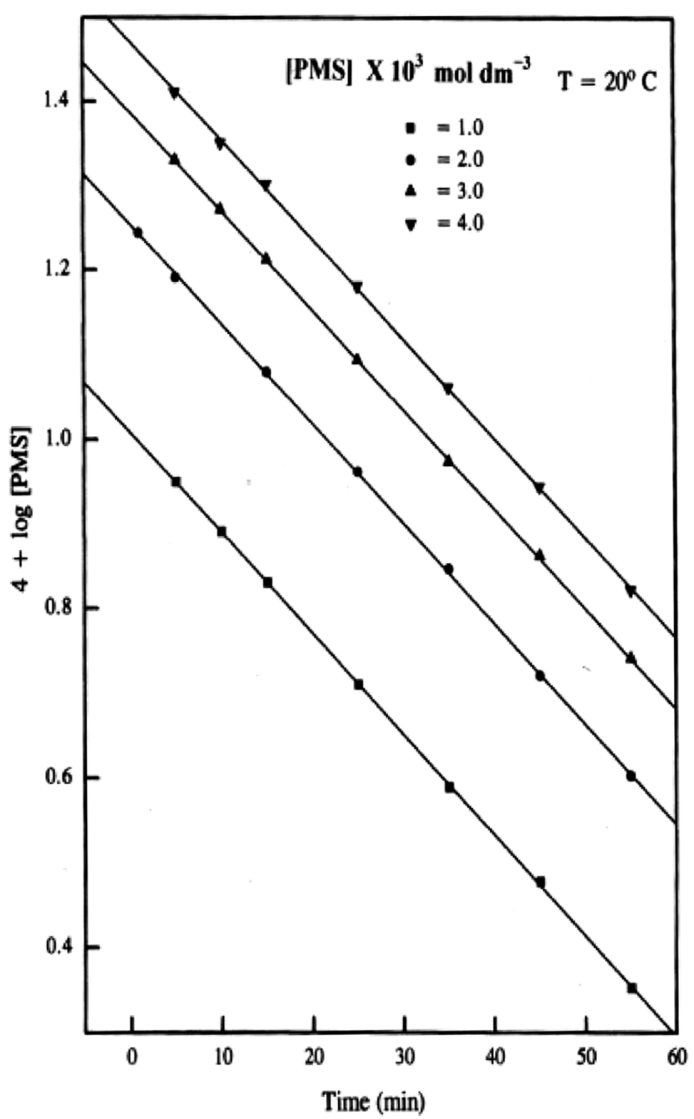

Fig. 4. Variation of [PMS].

(ii) Effect of [PMS $]_{0}$ : It is observed that the reaction rate was unaffected as evident from the constant slopes of $\log [\mathrm{PMS}]$ vs time plots for various [PMS $]_{0}\left(1.0 \times 10^{-3}-4.0 \times\right.$ $10^{-3} \mathrm{~mol} \mathrm{dm}^{-3}$ ) at fixed [Indole $]_{0},\left[\mathrm{H}^{+}\right]_{0}, \mu$, and percentage of acetonitrile (Table 2 (A) \& Fig. 4). This observation confirms the first-order dependence of rate on [PMS].

(iii) Effect of $\mu$ : The influence of ionic strength $(\mu)$ maintained by the addition of sodium bisulphate on the reaction rate was found to be negligible (Table 2(B)). This shows that the reaction occurs between a neutral species namely the Indole molecule and the mononegative ion $\mathrm{HSO}_{5}{ }^{-}$, the active species of the oxidant.

(iv) Effect of $\left[\mathbf{H}^{+}\right]$: The reaction rates measured at constant [Indole], [PMS], $\mu$, and percentage of acetonitrile but with various $\left[\mathrm{H}^{+}\right]\left(5 \times 10^{-3}-9 \times 10^{-2} \mathrm{~mol} \mathrm{dm}^{-3}\right)$ were found to be the same (Table 2(C)). Such a kinetic behaviour indicates the nonexistence of any protonation equilibrium with respect to both PMS and Indole under the present experimental conditions employed.

(v) Effect of Dielectric Constant: So as to determine the effect of dielectric constant (polarity) of the medium
Table 3. Effect of Acetonitrile

\begin{tabular}{cccc}
\hline \multirow{2}{*}{$\% \mathrm{CH}_{3} \mathrm{CN}$} & \multicolumn{3}{c}{$k^{\prime}\left(10^{4} \mathrm{~s}^{-1}\right)$} \\
\cline { 2 - 4 } & $283 \mathrm{~K}$ & $288 \mathrm{~K}$ & $293 \mathrm{~K}$ \\
\hline 40 & 5.5947 & 7.6714 & 9.6380 \\
50 & 3.0124 & 3.9412 & 4.5369 \\
55 & 1.9523 & 2.2831 & 3.2292 \\
60 & 1.0217 & 1.2052 & 1.4163 \\
\hline [Indole]: $3.0 \times 10^{-2} \mathrm{~mol} \mathrm{dm}^{-3},[\mathrm{PMS}]: 2.0 \times 10^{-3} \mathrm{~mol} \mathrm{dm}^{-3},\left[\mathrm{H}^{+}\right]:$ \\
$0.02 \mathrm{~mol} \mathrm{dm}{ }^{-3}, \mu: 0.3 \mathrm{~mol} \mathrm{dm}^{-3}$.
\end{tabular}

Table 4. Rate and Activation Parameters

\begin{tabular}{ccc}
\hline Temp $(\mathrm{K})$ & $k_{2}\left(10^{2} \mathrm{~mol}^{-1} \mathrm{dm}^{3} \mathrm{~s}^{-1}\right)$ & SD \\
\hline 283 & 1.0176 & \pm 0.0027 \\
288 & 1.2817 & \pm 0.0044 \\
293 & 1.5181 & \pm 0.0076 \\
\hline
\end{tabular}

$\overline{E_{a}}=27.62 \mathrm{~kJ} \mathrm{~mol}^{-1} ; \Delta H^{\#}=25.19 \pm 0.0067 \mathrm{~kJ} \mathrm{~mol}^{-1} ; \Delta S^{\#}=-275.07$ $\pm 2.0690 \mathrm{~kJ} \mathrm{~mol}^{-1} ; \Delta G^{\#}=105.78 \pm 0.9648 \mathrm{~kJ} \mathrm{~mol}^{-1}$.

on rate, the oxidation of Indole by PMS was studied in aqueous acetonitrile mixtures of various compositions (Table 3). The data clearly reveals that the rate increases with decrease in the percentage of acetonitrile, i.e. with increasing dielectric constant or polarity of the medium, and lead to the inference that there is a charge development in the transition state involving a more polar activated complex than the reactants, ${ }^{22}$ a neutral molecule (Indole), and a mononegative ion $\left(\mathrm{HSO}_{5}^{-}\right)$suggesting a polar (ionic) mechanism.

(vi) Rate and Activation Parameters: The effect of temperature on $k^{\prime}\left(\mathrm{s}^{-1}\right)$ was studied in the range of 283$293 \mathrm{~K}$ and the results are shown in (Table 4). The Arrhenius plot of $\log k_{2}$ vs $1 / T$ was linear. From the above plot, the values of energy of activation $\left(E_{a}\right)$ was calculated (Fig. 5 ). The value of $\Delta S^{\#}$ was computed from Eyring equation. The large negative value of entropy of activation $\left(\Delta S^{\#}\right)$ obtained is attributed to the severe restriction of solvent molecules around the transition state..$^{23}$

\section{Stoichiometry}

Solutions of Indole containing an excess of PMS were kept overnight at room temperature. Titrimetric estimation of the concentration of PMS consumed and assuming that all the Indole taken had reacted, the stoichiometry of Indole: PMS was found to be 1:2.

\section{Test for Free Radical Intermediates}

The observed total second-order dependence of rate, beside first-order dependence each on both [Indole] and [PMS], shows that the reaction involves a nonradical 


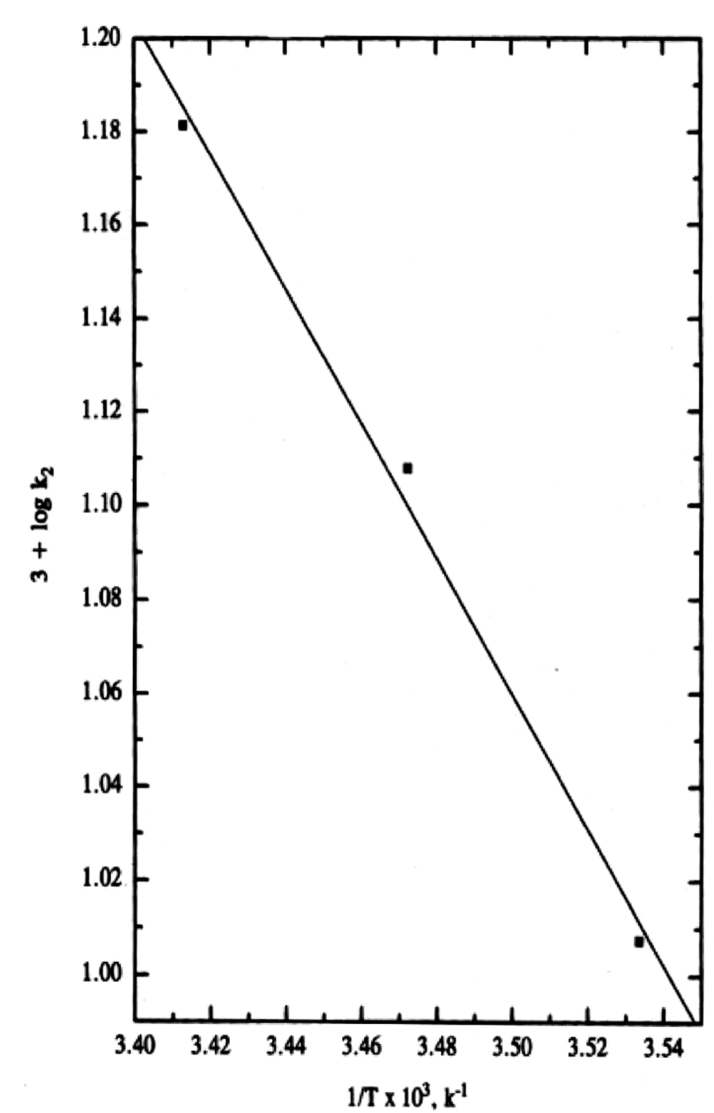

Fig. 5. Evaluation of Ea.

pathway. Moreover no polymer formation was observed when a freshly distilled acrylonitrile monomer was added to the deaerated reaction mixture indicating the absence of free radical intermediates.

\section{Rate Law}

In accordance with the above observations, the rate law for the disappearance of PMS is given as follows:

$$
\begin{aligned}
& -\mathrm{d}[\mathrm{PMS}] / \mathrm{dt}=2 k_{2}[\mathrm{PMS}][\text { Indole }] \\
& \text { rate } \left./[\mathrm{PMS}]=k^{\prime} \mathrm{s}^{-1}\right)=2 k_{2}[\text { Indole }] \\
& \text { (i:e:) } \mathrm{k}^{-1}=2 k_{2}[\text { Indole }]
\end{aligned}
$$

where $k^{\prime}=$ pseudofirst order rate constant and $k_{2}=$ second order rate constant.

\section{Mechanism}

Based on the foregoing observations such as firstorder dependence of rate each on [Indole], [PMS], zeroorder dependence on $\left[\mathrm{H}^{+}\right]$, negligible effect of $[\mu]$, and the stoichiometry, the following mechanism is suggested:

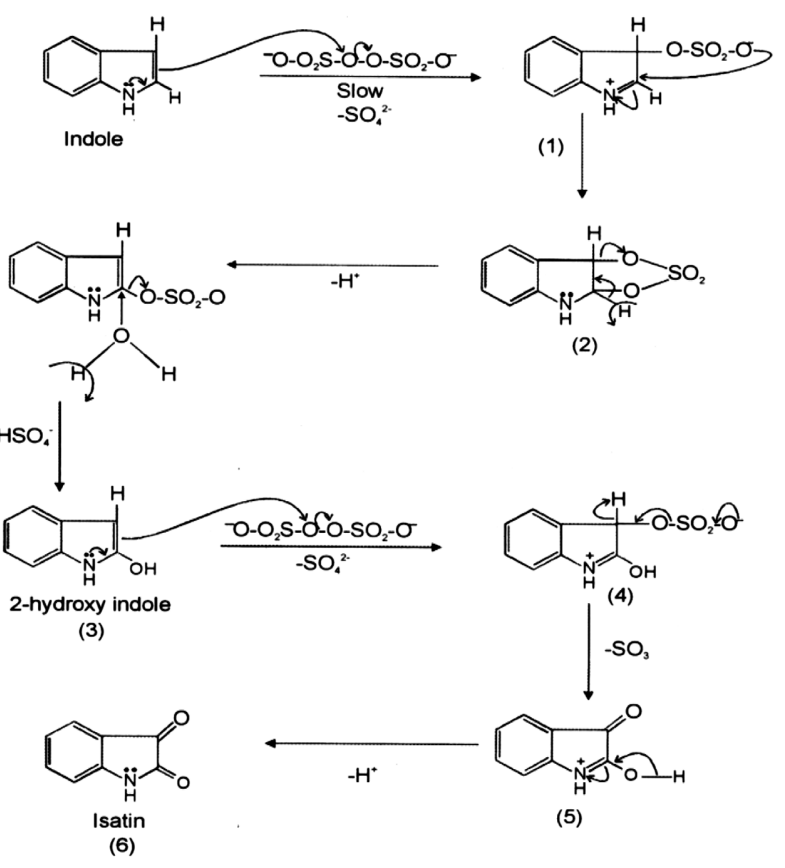

PMS ion is known to be a mild electrophilic reagent capable of substituting activated aromatic compounds. From our experimental results we suggest that the reaction proceeds through an electrophilic attack of the oxidant (PMS) at $\mathrm{C}-3$ by a mechanism involving nucleophilic displacement of peroxide oxygen ${ }^{31}$ to form Sulfuric acid mono(3H-indol-3-yl) ester (1) as the rate determining step. Such a similar electrophilic attack on the C-3 of indoles is supported by earlier reports. ${ }^{24}$ The compound (1) undergoes an intramolecular rearrangement to give 2-hydroxy-indole (3) through a cyclic intermediate (2). Infact, evidences for the involvement of a similar cyclic intermediate in the oxidations of $o$-benzoquinone, ${ }^{25}$ 3,5-dimethyl-2,6-diaryl 14-piperidone ${ }^{26}$ and 2,6-diphenyl-4-piperidones ${ }^{27}$ by PMS were obtained. The second PMS ion attacks the compound 3 to form 2,3-dihydroxy-indole (4) which gives isatin (6) has final products through the intermediate (5).

\section{Biological Activities of Isatin}

Central nervous system (CNS) depressant activities: Isatin has a range of actions such as CNS-MAO inhibition, anticonvulsant and anxiogenic activities. Its effect as a mono amino-oxidase (MAO) inhibitor is the most potent in vitro action recorded to date. It is a selective MAO B inhibitor with an inhibitory concentration $\left(\mathrm{IC}_{50}\right)$ of about $3 \mathrm{~g}$ $\mathrm{mL}^{-1} \cdot 28$

Anticonvulsant activity: Bhattacharya and Chakraborti ${ }^{31}$ reported isatin to be an endogenous compound with anxiogenic properties, which occur within a narrow intra-peri- 
toneal (i.p.) dose range (15-20 $\left.\mathrm{mg} \mathrm{kg}^{-1}\right)$. Bhattacharya et al. ${ }^{32}$ have found isatin to function as a potent antagonist on anti-natriuretic peptide (ANP) receptors in vitro, and to inhibit anxiolytic, memory facilitating and diuretic actions of intracerebroventricularly administered ANP. Blackburn et al. ${ }^{33}$ reported that indoles, such as 1-5-(2-thienyl methoxy1H-indol-3-yl) propan-2-amine, were used in the treatment and prevention of epilepsy and mi-graine. Isatin has also been found to increase vigilence. ${ }^{29}$ At a low dose (15 mg $\left.\mathrm{kg}^{-1}\right)$, it is anxiogenic and prolongs pentylenetetrazole (PTZ) induced seizures while athigher dosage $\left(80 \mathrm{mg} \mathrm{kg}^{-1}\right)$ it becomes sedative and anticonvulsant and the brain 5HT levels are found to be significantly raised. ${ }^{30}$

Acknowledgments. The publication cost of this paper was supported by the Korean Chemical Society.

\section{REFERENCES}

1. Goyal, R. N.; Aditisangal Electrochem. Acta 1994, 50, 2135.

2. Xu., J.; Hou, J.; Zhou, W.; Nie, G.; Pu, S.; Zhang, S. Spectrochim. Acta, Part A 2006, 63, 723.

3. Jennings, P.; Jones, A. C.; Mount, A. R.; Thomson, A. D. J. Chem. Soc. Faraday. Trans. 1997, 93, 3791.

4. Suárez-Castilho, O. R.; Beiza-Granados, L.; MeléndezRodriǵuez M.; Alvarez-Hernández, A. J. Nat. Prod. 2006, 69, 1596.

5. Rangappa, K. S.; Esterline, D. T.; Mythily, C. K.; Mahadevappa, D. S.; Ambedkar, S. Y. Polyhedron 1993, 12, 1719.

6. Meenakshisundaram, S.; Sarathi, N. Indian J. Chem. 2007, 46A, 1778 .

7. Corbett, M. D.; Chipko, B. R. Biochem. J. 1979, 183, 269.

8. Burd, V. N.; Bantleon, R.; Van Pee, K. H. Applied Biochemistry and Microbiology 2001, 37(3), 248.

9. Gillam, E. M.; Notley, L. M.; Cai, H.; De Voss, J. J.; Guengerich, F. P. Biochemistry 2000, 39(45), 13817.

10. Bora, U.; Chaudhuri, M. K.; Dey, D.; Dhar, S. S. Pure. Appl. Chem. 2001, 73, 93.

11. Kajigaeshi, S.; Kakinami, T.; Okamoto, T.; Fujisaki, S. Bull. Chem. Soc. Jpn. 1987, 60, 1159.

12. Harrod, J. F.; Guerin, C. Inorganica Chemica Acta 1979, 37, 141.

13. Pressey, R. J. Mol. Catal. 1991, 70, 243.

14. Hinman, R. L.; Lang, J. Biochemistry 1965, 4, 144.

15. Koch, J. L.; Oberlander, R. M.; Tamas, I. A.; Germain,J. L.; Ammondson, D. B. S. Plant Physiol. 1982, 70, 414.

16. Gazaryan, I. G.; Chubar, A.; Mareeva, E. A.; Lagrimini, L. M.; Van Huystee, R. B.; Thorneley, R. N. F. Phy- tochemistry 1999, 51, 175.

17. (a) Gazaryan, I. G.; Lagrimini, L. M.; Ashby, G. A.; Thorneley, R. N. F. Biochem. J. 1996, 313, 841 (b) Ricard, J.; Job, D. Eur. J. Biochem. 1974, 44, 359 (c) Gazarian, I. G.; Lagrimini, L. M.; Mellon, F. A.; Naldrett, M. J.; Ashby, G. A.; Thovneley, R. N. F. Biochem. J. 1998, 333, 223.

18. Hu, T.; Dryhurst, G. J. Electro. Anal. Chem. 1997, 7, 432.

19. (a) Ghamem, R.; Carmona, C.; Munoz, M. A.; Guardado, P.; Balon, M. J. Chem. Soc., Perkin Trans 2 1996, 2197 (b) Carmona, C.; Balon, M.; Munoz, M. A.; Guardado, P.; Hidalgo, J. J. Chem. Soc., Perkin Trans 2 1995, 331 (c) Balon, M.; Munoz, M.; Guardado, P.; Hidalgo, J.; Carmona, C. J. Org. Chem. 1993, 58, 7469.

20. Maruthamuthu, P.; Neta, P. J. Phys. Chem. 1997, 81, 937. 21. Montgomery, R. E. J. Am. Chem. Soc. 1979, 96, 7820.

22. Laidler, K. J. Chemical Kinetics; Tata-McGraw Hill: New Delhi, 1965; p 229.

23. Anis, S. S. J. Chim. Phys. 1992, 89, 659.

24. (a) Behrman, E. J.; Edwards, J. O. Prog. Phys. Org. Chem. 1967, 4, 93 (b) Curi, R.; Edwards, J. O. In Organic Peroxides; D. Swern, Ed.; Wiley: New York, 1970; Vol.1, Chapter IV (c) Katritzky, A. R.; Rees, C. W. Comprehensive Heterocyclic Chemistry; Pergamon Press: London, 1984; Vol. 4, p 205 (d) Jackson, A. H.; Lynch, P. P. J. Chem. Soc. Perkin Trans 2 1987, 1215.

25. Ando, W.; Miyazaki, H.; Akasaka, T. J. Chem. Soc. Chem. Commun. 1983, 518.

26. Meenal, K. R.; Ramanivimala, G. J. Ind. Chem. Soc. 1994, $71,609$.

27. Meenal, K. R.; Ramanivimala, G. J. Ind. Chem. Soc. 1997, 74, 43.

28. Glover, V.; Halket, J. M.; Watkins, P. J.; Clow, A.; Goddwin, B. L.; Sandler, M. J. Isatin: identity with the purified endogenous monoamine oxidase inhibitor tribulin. $\mathrm{Neu}$ rochemistry 1988, 51, 656.

29. Seidel, J.; Wenzel, J. Some histochemical and electrophysiological effects of isatin. Pol. J. Phar-macol. 1979, $35,407$.

30. Mc Intyre, I. M.; Norman, T. R. Seratonergic effects of isatin: An endogenous MAO inhibitor related to tribulin. J. Neural. Transm. 1990, 79, 35.

31. Bhattacharya, S. K.; Chakraborti, A. Dose related proconvulsant and anticonvulsant activity of isatin, a putative biological factor in rats. Indian. J. Exp. Biol. 1998, 36, 118.

32. Bhattacharya, S. K.; Anticonvulsant activity of intraventricularly administered atrial natriuretic peptide and its nhibition by isatin. Biog. Amines 1988, 14, 131.

33. Blackburn, T.; Paul, K.; Smith, G. Medicaments for Treatment of Migraine, Epilepsy and Feeding Disorders. G. B. Pat. 9,425,012, 28 Apr 1993; ref. Chem. Abstr. 1995, 122, $72046 \mathrm{e}$. 